\title{
Fuzziness in LGBT Non-Profit ICT Use
}

\author{
Ryan Champagne \\ University of Pittsburgh \\ 135 North Bellefield Avenue, \\ Pittsburgh, PA 15260 \\ rkc12@pitt.edu
}

\author{
Julio Guerra \\ University of Pittsburgh \\ 135 North Bellefield Avenue, \\ Pittsburgh, PA 15260 \\ jdg60@pitt.edu
}

\author{
Chun-Hua Tsai \\ University of Pittsburgh \\ 135 North Bellefield Avenue, \\ Pittsburgh, PA 15260 \\ cht77@pitt.edu
}

\author{
Jocelyn Monahan \\ University of Pittsburgh \\ 135 North Bellefield Avenue, \\ Pittsburgh, PA 15260 \\ jom99@pitt.edu
}

\author{
Rosta Farzan \\ University of Pittsburgh \\ 135 North Bellefield Avenue, \\ Pittsburgh, PA 15260 \\ rfarzan@pitt.edu
}

\begin{abstract}
This note reports on the use of ICTs by a small nonprofit organization that serves LGBT youth. Our work centers on a reflective evaluation of the use of online communities for LGBT community through qualitative interviews with the organization. Perceived issues around ICT use in the organization were shaped by the blurred lines between professional and personal interactions online, the small size of the community and ubiquity of social media use, and ambivalence of members toward online communication. The project models one way for researchers in ICT4D to work within communities to develop an understanding of self-identified issues in vulnerable populations.
\end{abstract}

\section{Categories and Subject Descriptors}

K.4.2 [Computers and Society]: Social Issues

\section{General Terms}

LGBT, ICT4D, Fuzziness

\section{Keywords}

LGBT, ICT4D, Fuzziness, Community Development

\section{INTRODUCTION}

Members of the LGBT community face daily hostility in the United States. National statistics support this unfortunate reality: a 2013 PEW Research study reports the acceptance of homosexuality in the US is only $60 \%$ and the rejection rate is around 33\% [6]. Ray and Berger [10] report that between 20 and $40 \%$ of homeless youth identify as LGBT. These high numbers are primarily due to family

Permission to make digital or hard copies of all or part of this work for personal or classroom use is granted without fee provided that copies are not made or distributed for profit or commercial advantage and that copies bear this notice and the full citation on the first page. Copyrights for components of this work owned by others than ACM must be honored. Abstracting with credit is permitted. To copy otherwise, or republish, to post on servers or to redistribute to lists, requires prior specific permission and/or a fee. Request permissions from Permissions@acm.org.

ICTD '15, May 15 - 18, 2015, Singapore, Singapore

Copyright 2015 ACM 978-1-4503-3163-0/15/05...\$15.00

http://dx.doi.org/10.1145/2737856.2737893 conflict: $26 \%$ of gay teens who came out to their parents were kicked out of their homes. The consequences of this widespread hostility are particularly grim for transgender and gender-nonconforming people, $41 \%$ of which attempt suicide at least once [5]. Health issues are also a major issue for LGBT youth, particularly those who are kicked out. Homeless LGBT youth are three times as likely to participate in sex for survival, and $50 \%$ of homeless youth believe they will someday test positive for HIV [10]. In light of these statistics, it's not surprising that LGBT minorities seek out and create "safe" spaces, places that are more than spaces for interaction and become alternative family environments that provide emotional support and acceptance of their identities. Because this community is so vulnerable, it makes it particularly important to be attentive to issues of health, safety and networks of communication that arise.

This paper concerns our work with Health House ${ }^{1}$, a nonprofit organization that serves young men of color who have sex with men (MSM) and trans women of color in Pittsburgh, Pennsylvania. Health House provides health services, HIV testing and counseling. It is situated in an open studio space where health services and counseling are provided, which also doubles as a safe community space and a "house" for the community to hang out and participate in events as one staff member described, "a safe space for them to be themselves: the good, the bad, and the ugly."

One important factor influencing Health House activities is the complex nature of relationships between staff and patients, especially for those members of staff that also identify as part of the community. For instance, one can be friends with people in the community and hang out as part of their social group, but also participate in a professional capacity (such as offering medical advice or legal consultation). Personal relationships and professional interactions blur, and, to use a term that came up in early interviews with staff, there is a "fuzziness" that governs interactions and adds layers of difficulty to the navigation of the complex web of relationships and interactions that occur within the space

Mediation of those relationships through ICTs can make

${ }^{1}$ This is a pseudonym name of the organization. 
these boundaries even fuzzier than before as professional and personal relationships are played out in virtual spaces as well - sometimes in the same space at the same time. Particularly in the realm of health services, there are growing concerns about the ethics of personal and professional communication online [1]. Although social media and virtual social communities can make communication and building connections quicker and more convenient, they also represent a risk of disclosure and privacy issues.

Networked ICTs also bring with them another type of "fuzziness": the increasing blurring of online and offline identities with the rise of social media. This is particularly true for LGBT youth, who often use online communication to supplement their perceived limited offline exposure to other members of the community [3]. GLSEN et al. [4] found that half of LGBT youth with less offline community participation connected with other community members online, and $14 \%$ said they had "first disclosed their LGBT identity to someone online". Unfortunately, the study also found that LGBT youth are much more prone to being harassed online - almost three times as likely as non-LGBT youth. In the context of high suicide and homelessness rates, the balance between online community building and online harassment carries very high stakes for vulnerable LGBT youth.

It is this delicate communications scenario which motivates us to investigate the role that ICTs play in Health House. This research aims to understand the ways that patterns and hidden risks for LGBT community members affect decisions about uses of ICT applications within Health House. We propose the following questions:

Q1: How are ICTs being used within the organization across different roles? What are some of the issues that affect its use, both individually and across the organization?

Q2: How do members of the organization with different levels of access to ICTs \& the community negotiate "fuzziness" between personal and professional lives, and between the online / offline life of the community?

While previous work has been done on ICT adoption in nonprofit organizations $[2,8,9,7]$, fewer studies have focused on organizations serving LGBT communities in particular. This project adds to the literature on information communication technologies for development by considering a unique case study using a ground-up approach. A deeper goal of our project is to show how in the process of this work our understanding and goals shifted as we listened to our participants (Health House staff), from a broad, vague conception of the "important" factors and problems to target the relevant issues from Health House's perspective. Rather than aiming to target and solve a particular ICT need in a community, this project is designed to help Health House reflect on their use of ICTs and work with them to assess self-identified issues and concerns. This paper accounts for some of what we found in working with the organization, but also reflects on the changes made to the project as the research team engaged more deeply with the community. Our hope is to demonstrate how reflection in ICT4D projects is an important step that can lead to deeper, more productive conversations with the community, and ultimately help to avoid failures in adoption and implementation.

\section{COMMUNITY PROFILE}

Health House is a small non-profit organization in Pittsburgh that serves younger gay men and trans women of color. Health House offers health resources such as testing and counseling, and also provides a community space for socializing and events. Health House has a small but diverse staff that includes administrators, health workers, and counselors across a variety of ages and genders. Some of the staff members identify themselves as part of the community they serve and others do not (a boundary created primarily by age); some staff also interact more closely with visitors to Health House than others.

The community that Health House serves is fairly small. Participants in our study estimated it comprises approximately 150 people. Both the community and the organization are extremely tight-knit as a result. The organization is linked to house and ball communities, a network of social organizations that foster self-expression and performance in safe spaces. Primarily a venue for drag performance, the houses, or small groupings of closely associated individuals, become a family by design. People within one house support one another through strong emotional bonds and a collective support network to negate the marginalization and adversity that they encounter as part of daily life. One moving example of this community is depicted in the acclaimed documentary Paris Is Burning (1990) which shows how LGBT groups find a family in house and ball communities. Beyond providing health services, Health House works to build and maintain a community network that, as one participant put it, provides the "kids" with "a family."

\section{METHODOLOGY}

The original vision of this project focused on the types of social media Health House used, which communication strategies the organization employs to guide use of ICTs, and how the organization represented itself and its mission online. Potential issues we identified for investigation included the divide between community members online and offline, additional ICTs used by the organization that we had not observed, types of online communication, collaborative tools, and scope of online outreach.

After designing a research plan to investigate the roles that ICTs play in linking Health House and the communities that it serves, we contacted the organization to meet and discuss the project. Through those meetings, other more pressing areas for investigation became obvious, and we amended our initial research design. Generally, Health House staff members found value in exploring the role that ICTs play in connecting communities and services. Through conversation, members identified other emergent properties about ICT use in a nonprofit organization that is embedded in small communities. Specifically, Health House staff noted that professional and personal lines are blurred by "fuzziness," when professional work is administered alongside personal relationships. Staff members universally commented that their work and their personal lives collide when communication exits the realm of defined boundaries and enters the world of undefined interaction; this collision was especially apparent on social media, particularly Facebook. 
Unexpectedly, our work shifted from an exploration into how ICTs may bridge isolation and marginalization and foster community building and acceptance into work that instead delved into a conversation about the grey areas that emerge through the "fuzzy" arena of digitally-mediated communication. This offered our group the opportunity to engage in a conversation that carried value to the organization with whom we were working. After the first meeting that we had with Health House staff, "communication" as an organizing concept was displaced by "fuzziness." Our work was reoriented to look not at how ICTs engage communities, but rather how ICTs are embedded in communities and how, despite boundaries, fluid interaction permeates personal and professional communication.

In trying to understand how Health House staff experienced "fuzziness," we gathered data from the organization's members through semi-structured interviews $(n=6)$. Interview topics included individual ICT use, unused technologies, and limitations and influencing factors. Two layers of staff, a "back of house" administrative staff and a "front of house" service staff, shared their experiences. Interviews were conducted both at the project facility and at a university office setting, and lasted approximately an hour.

\section{ANALYSIS \& ISSUES}

Members of Health House shared a spectrum of relationships with ICTs that were deeply impacted by "fuzziness," understandings of ICTs' roles in the communities they served, and sensitivity to potential dangers raised by online communication in particular. Members in different roles at the organization experienced these issues in different ways, particularly those who worked directly with visitors to Health House (such as counselors) vs. those who primarily worked in administration.

\section{Fuzziness}

Some participants felt that the "fuzziness" of personal and professional relationships was central to their experience with technology at the organization - maintaining distinctions between them, one staff member said, "is one of the hardest roles and realities" of the job. For peer counselors, it was particularly difficult, because they worked more closely with visitors and were often closer to them in age and experience. It could be frustrating for visitors because it put counselors in an authority position and generated tension - as articulated by one counselor, "Why are you in this position of power and I am not?"

Many staff members - primarily on the administrative side distanced themselves from fuzziness by explaining that they weren't part of the community they served, often citing age as the reason they were different. One participant said, "I don't have the fuzziness because of the age difference. I treat them as kids." Another said "it's not my place to do that" when it came to interacting with visitors through social media. However, most of the staff members who used Facebook did add community members to their personal Facebook page, and did not create a separate page for their work at Health House.

Boundaries and boundary-making came up many times through- out the interviews, particularly when it came to the use of mobile technology. One administrator said that he gave his cell phone number to other professionals, but not to visitors in the space, because they had the training to understand boundaries and use his number respectfully. Other members did use text messaging and phone calls to keep in touch with community members, although they said they did sometimes have to set boundaries about appropriate contact.

While the initial use of "fuzziness" was to describe the blurred boundaries between personal and professional relationships online, our research team also used the term to describe another phenomenon we observed: the confused relationship between online and offline life for the organization and the community.

\section{Technology and the Community}

One of the strongest messages that emerged throughout the interviews was the complex, "fuzzy" nature of the community's relationship with technology. Mobile technology and Facebook were common topics of conversation. Visitors to the Health House space are required to fill out a sign-in form either on a tablet or on their mobile phone, and are encouraged to provide their Facebook address. One member of the administration said that Facebook contact was important because people in precarious positions might lose their phone access or change their number frequently - Facebook was a more stable option for communication.

Health House maintains three Facebook pages: two for private use within the organization's members and their visitors, and one public outreach page where events are posted. They also have an open blog and Twitter, neither of which are updated frequently. Several participants indicated they believed that because the community was so small, information about organization would spread quickly by word of mouth, so outreach wasn't as high a priority as keeping in contact with visitors. One member of the administration said that the organization had reached the "saturation point" of outreach to the community early on.

One potential issue raised was that minimizing outreach on social media might make it difficult to reach members of the community who had lower access to common knowledge about organizations and events. Two possible groups this might impact were named. The first was members of the "down low" community, or "DL": MSM who prefer to keep their sexual activities with men private. The other was people visiting from out of town who might need access to health services, but would not be plugged into local knowledge.

A number of other technologies in personal use also came up briefly in interviews, including other social media such as Instagram and dating applications (e.g. Grindr, BGCLive). Although many community members and some staff members use the applications, the organization has not yet begun to use them for outreach or services/event advertising. Overall, participants seemed to agree that technology was a huge part of communication within the community, but were less sure about how the organization was mobilizing, or should mobilize, online communication. 
While technology was generally viewed as ubiquitous or important in the community, personal attitudes toward it were often ambivalent. Some staff members indicated that they regularly used ICTs to communicate with participants, but others didn't use it at all or were leery of posting personal information online. "You have to be aware, it has danger," said one counselor, who said he advised kids, "do not put anything personal on this site."

Two major recent events in the local MSM community came up in multiple interviews and, said at least one participant, had an impact on decisions about how ICTs were used at Health House. In one case, a community member posted a number of pornographic videos of sexual encounters with men who were DL and didn't openly advertise their interest in other men. In some cases, the videos were sent to the men's families or partners on social media. Most recently, a local man had gone missing and Health House had been alerted to it by concerned friends posting on social media. Concern on his page was accompanied by derogatory comments about his sexual habits.

Reactions to these events not only caused pause in Health House about adopting new online ICTs, but also made their way into conversation with visitors to the space. Different staff members had very different attitudes toward how these and other online conflicts made their way into the space. One peer counselor said that when people had online conflicts and tried to bring them to the physical space at Health House, he asked them to leave them at the door. Another counselor said that moments of online conflict and danger were an opportunity to have a conversation, and that group discussion was an opportunity to mediate tensions and fears.

\section{DISCUSSION}

Drawing on the interviews, we created a preliminary map that reflects the relationships between the Health House physical space, online space, and larger communities.

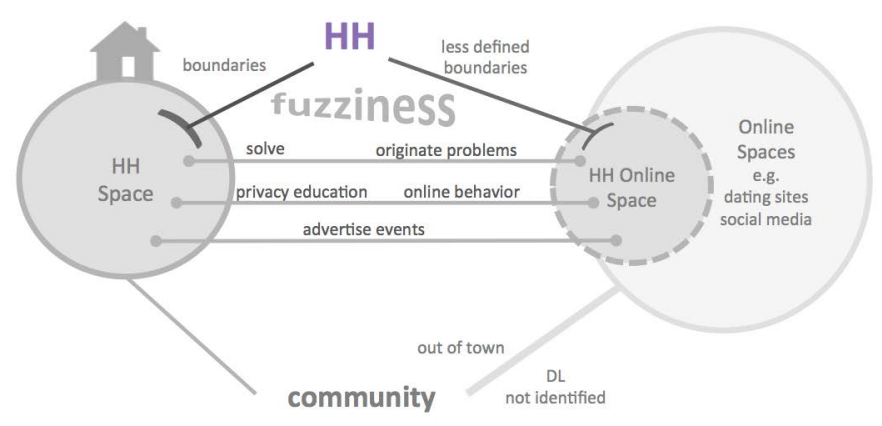

Figure 1: Research finding of Project finding.

Moving forward with our project, there are also a number of challenges that our research team has identified. We have offered to produce a final report evaluating the results of our interviews to Health House, and to possibly move forward with publication. Creating the report will require drawing on what we have learned from the community to honestly evaluate what they have told us and to reflect their experi- ences accurately. It is also important to produce a document that everyone in the organization across multiple levels of education and expertise can read and learn from.

In working with Health House, we have tried to emphasize the importance of thoughtfully listening to the community in ICT4D research and using their input to shape the ways we approach and report our project. We recommend that future work with vulnerable populations, particularly LGBT communities, also draw on similar practices to understand the different issues in communities that can shape decisions about ICT use. This project ends where many ICT4D projects begin: by assessing and creating recommendations for a community. Challenges in design and implementation, particularly when working with vulnerable populations, might be addressed by working closely with organizations and communities to learn about the different issues that impact decisions they make about ICT use.

\section{REFERENCES}

[1] K. C. Chretien and T. Kind. Social media and clinical care ethical, professional, and social implications. Circulation, 126(13):1413-1421, 2013.

[2] K. Corder. Acquiring new technology comparing nonprofit and public sector agencies. Administration \& Society, 33(2):194-219, 2001.

[3] S. DeHaan, L. E. Kuper, J. C. Magee, L. Bigelow, and B. S. Mustanski. The interplay between online and offline explorations of identity, relationships, and sex: A mixed-methods study with lgbt youth. Journal of Sex Research, 50:421-434, 2013.

[4] GlSEN, CiPHR, and CCRC. Out online: The experiences of lesbian, gay, bisexual and transgender youth on the internet. New York: GLSEN, 2013.

[5] A. P. Haas, P. L. Rodgers, and J. L. Herman. Suicide attempts among transgender and gender non-conforming adults. work, 50:59, 2014.

[6] A. Kohut. The global divide on homosexuality: Greater acceptance in more secular and affluent countries. Washington, DC: Pew research center, 2013.

[7] C. A. Le Dantec and W. K. Edwards. The view from the trenches: Organization, power, and technology at two nonprofit homeless outreach centers. In Proceedings of the 2008 ACM conference on Computer supported cooperative work, pages 589-598. ACM, 2008.

[8] E. Lettieri, F. Borga, and A. Savoldelli. Knowledge management in non-profit organizations. Journal of Knowledge Management, 8(6):16-30, 2004.

[9] C. Merkel, U. Farooq, L. Xiao, C. Ganoe, M. B. Rosson, and J. M. Carroll. Managing technology use and learning in nonprofit community organizations: Methodological challenges and opportunities. In Proceedings of the 2007 symposium on Computer human interaction for the management of information technology, page 8. ACM, 2007.

[10] N. Ray and C. Berger. Lesbian, gay, bisexual and transgender youth: An epidemic of homelessness. National Gay and Lesbian Task Force Policy Institute, 2007. 